\title{
Variations in visual acuity, refraction, and corneal curvature with changes in applanation tension
}

\author{
D. POINOOSAWMY AND J.A. ROTH
}

Reading, Berks

During investigations on patients suspected of having glaucoma, it was noticed that the visual acuity varied from time to time and that the variations could be related to changes in intraocular pressure. This study was designed to evaluate and quantify this phenomenon; although no direct cause was found we believe our findings to be of interest.

Although loss of accommodation and blurring of vision are often cited as symptoms of chronic simple glaucoma, there are no reports of refraction changes due to changes in intraocular pressure. The literature deals mainly with changes observed in enucleated eyes or parts of eyes under different mechanical stresses. There is no doubt that the cornea and sclera are distensible (Gloster, Perkins, and Pommier, 1957) and that the volume of the eye is increased when intraocular pressure is raised (Greeves, 1913; Perkins and Gloster, 1957) and that these findings relate in some ways to the present work. There are many factors which may influence scleral rigidity and hence distensibility, but the reports in the literature are conflicting and are not helpful in the evaluation of our results (Friedenwald, I937; Draeger, I959; Drance, I96o; Graham and Hollows, I964; Mehra, I965).

\section{Methods}

Patients were selected for study from the Glaucoma Clinic at the Institute of Ophthalmology. All had open angles on gonioscopy and were being investigated for chronic simple glaucoma. None was receiving or had received glaucoma therapy. All had visual acuities of at least 6/6o (with distance correction if worn) and none had any corneal lesion which would hinder the accuracy of measurements of corneal thickness and anterior chamber depth.

Observations were made of 42 eyes in the following sequence:

(a) Visual acuity with distance correction (if worn) on a standard Snellen chart at 6 metres

(b) Keratometry in the vertical and horizontal meridia (Javal-Schiötz Ophthalmometer)

(c)* Anterior chamber depth

$(d) *$ Corneal thickness

$(e) *$ Applanation tensions.

* $(c),(d)$, and $(e)$, were measured using the appropriate attachments on the Haag-Streit 900 slit-lamp

Address for reprints: Dr. J. A. Roth, 70 Redwood Avenue, Woodley, Nr Reading, Berks 
Observations at different tensions were achieved by recording these measurements at different times of day during phasing or the water-drinking test. The measurements were made at hourly or 2-hourly intervals in patients undergoing phasing; and before the ingestion of water and at 30 minutes after, in patients undergoing the water-drinking test. (In the latter group applanation was performed at I5-minute intervals in the usual way.)

If visual acuity changed at any time, spherical lenses were placed before the eye, either in a trial frame or held in front of and in contact with the patient's own distance correction spectacles. The aim was to determine the power and sign of the lens required to restore visual acuity to its previous level. The lenses used were in the range $\pm 0 \cdot 12,0 \cdot 25,0 \cdot 50,0 \cdot 75, \mathrm{I} \cdot 00,1 \cdot 25$, and $\mathrm{I} \cdot 50 \mathrm{D}$.

Data recorded at the highest and lowest applanation tensions were studied.

\section{Results}

\section{Visual acuity}

No change occurred in seventeen eyes, while 25 eyes became relatively myopic.

Fig. I shows the distribution of visual acuities at the minimum and maximum recurded tensions and illustrates the tendency for a raised tension to produce a reduction in visual acuity.

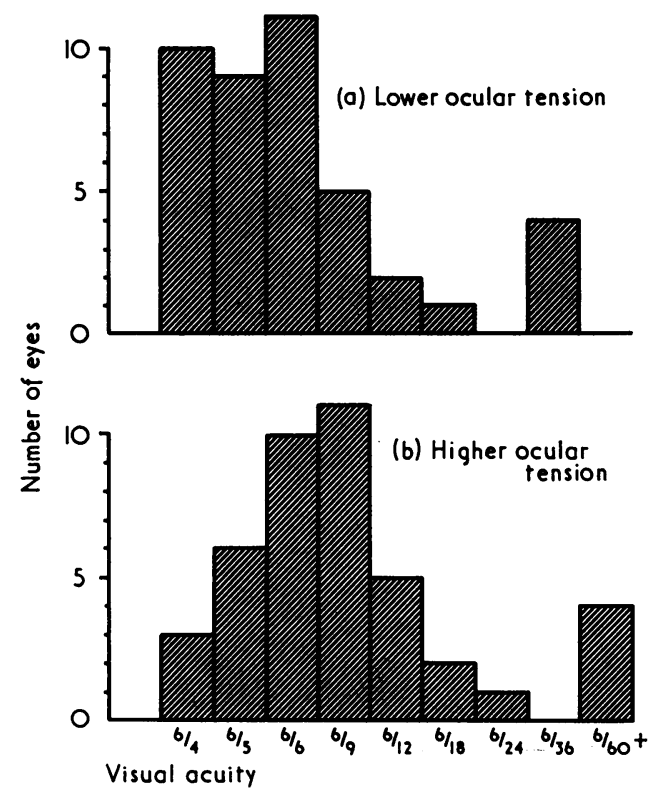

FIG. I Distribution of visual acuities at (a) lower tension, (b) higher tension

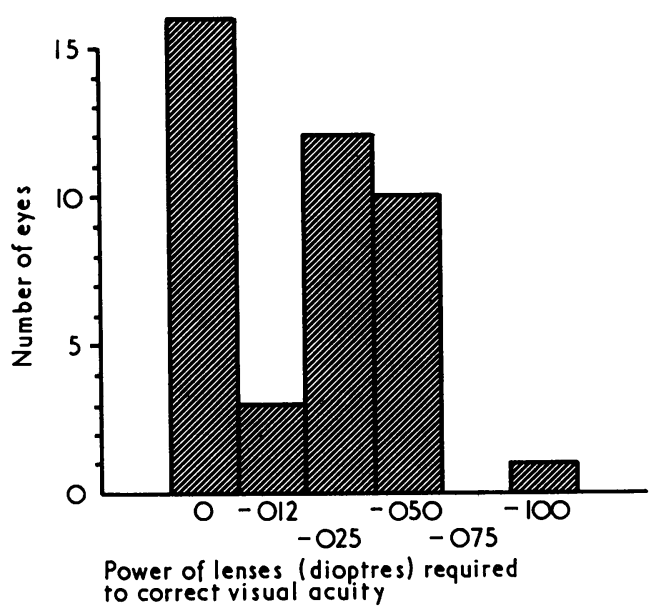

FIG. 2 Powers of lenses used to bring visual acuity back to its original level after tension was raised

Fig. 2 shows that when change occurred minus lenses were required to restore visual acuity to its previous level.

\section{Applanation tension}

Lower range: ${ }^{\circ}-3^{2} \mathrm{~mm} . \mathrm{Hg}$. Mean: $20 \cdot 4 \mathrm{I} \pm 4 \cdot 00$ (S.D.)

Higher range: $12-52 \mathrm{~mm} . \mathrm{Hg}$. Mean: $27 \cdot 40 \pm 6 \cdot 83$ (S.D.)

$t$ value: $5 \cdot 645$; i.e. there was a very significant difference between the highest and lowest tensions at which the two observations were made $(0 \cdot 0 \mathrm{I}>\mathrm{P}>\mathrm{O})$ 


\section{Corneal thickness}

No change

Range: $0.50-0.60 \mathrm{~mm}$. Mean: 0.55 \pm 0.02 (S.D.)

\section{Anterior chamber depth}

No change

Range: $2 \cdot 35-4 \cdot 20 \mathrm{~mm}$. Mean: $3 \cdot 16 \pm 0 \cdot 54$ (S.D.)

\section{Keratometry}

In three eyes there was no change in either meridian. All the other eyes shows an increase in radius of corneal curvature in one or both meridia, with the exception of one eye which showed a decrease in radius of curvature in the vertical meridian but an increase in the horizontal.

\section{HORIZONTAL MERIDIAN}

Lower range of pressure: $7 \cdot 25$ to $8 \cdot 20 \mathrm{~mm}$ radius of curvature. Mean: $7 \cdot 75 \pm 0 \cdot 23$ (S.D.)

Higher range of pressure: 7.35 to $8.25 \mathrm{~mm}$ radius of curvature. Mean: $7 \cdot 83 \pm 0 \cdot 23$ (S.D.)

Mean change: $0 \cdot 069 \pm 0 \cdot 055$ (S.D.)

\section{VERTIGAL MERIDIAN}

Lower range of pressure: $\mathbf{7 \cdot 2 0}$ to $\mathbf{8 \cdot 2 0} \mathrm{mm}$ radius of curvature. Mean: $7 \cdot 71 \pm 0 \cdot 23$ (S.D.)

Higher range of pressure: $7 \cdot 25$ to $8 \cdot 35 \mathrm{~mm}$ radius of curvature. Mean: $7 \cdot 76 \pm 0 \cdot 27$ (S.D.)

Mean change: $0 \cdot 069 \pm 0 \cdot 057$ (S.D.)

When the significance of the change in each meridian was compared with 0 , in the horizontal meridian $t=8 \cdot 238$, and in the vertical meridian $t=8 \cdot 296$;

i.e. the changes were highly significant $(0 \cdot 0 \mathrm{r}>\mathrm{P}>0)$. The distribution of these changes is shown in Fig. 3.

When correlation coefficients $(r)$ were calculated for changes in tension against changes in radius of curvature, in the horizontal meridian $r=0.665$, and in the vertical meridian $r=0.577$;

i.e. the radius of corneal curvature increased when the intraocular pressure was raised in both meridia.

\section{Discussion}

The results show that most of the eyes in this study became relatively myopic when the tension was raised. (Change in visual acuity is shown in Figs $\mathrm{r} a$ and $b$ and change in refraction in Fig. 2.) About one-third showed no change in visual acuity and none tended to become hypermetropic. There is a fairly close relationship between rise in tension and change in corneal curvature, as evidenced by the correlation coefficients produced, but this demonstrates a paradox. The corneae became relatively flatter and hence less powerful but the eyes became relatively myopic.

Myopia could be caused by a number of changes in the eye:

\section{(a) Corneal curvature}

In order to produce relative myopia, the radius of curvature of the cornea would need to be 


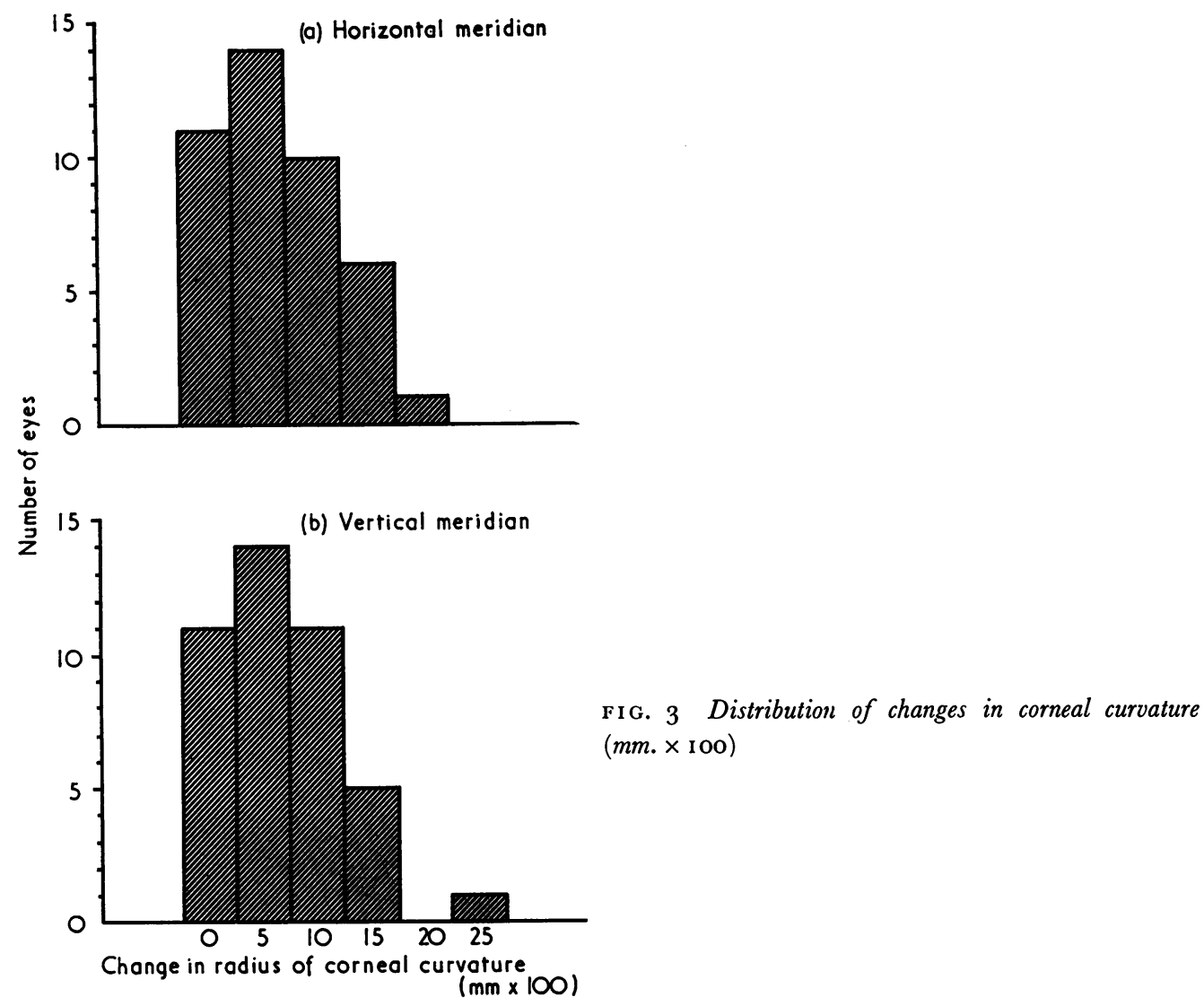

decreased in order to make its effective power greater. The reverse effect occurred.

It is possible that applanation tonometry produced prolonged corneal flattening, but in eight eyes in which applanation tension did not change there was no change in corneal curvature. We do not think, therefore, that the changes in corneal curvature were related to effects produced by applanation.

\section{(b) Anterior chamber depth}

There was no change in depth at the centre of the anterior chamber although there could have been change more peripherally that escaped detection. There are three possible interpretations of this:

(I) Change occurred but was too small to be measured.

(2) The floor of the anterior chamber (i.e. the anterior surface of the lens) moved posteriorly by the same amount as the cornea was flattened.

(3) The limbus moved anteriorly relative to the visible part of the lens capsule.

If ( $\mathrm{I}$ ) occurred the change must have been less than $0 \cdot 1 \mathrm{~mm}$. otherwise it would have been detected. This is possible but would not account satisfactorily for some of the larger changes in refraction observed. The second alternative is also possible. If the floor of the anterior chamber moved posteriorly, either the whole lens moved posteriorly or it became thinnerboth of which effects would tend to produce relative hypermetropia. In order to produce myopia the lens would need to become thicker and/or it would need to be displaced anteriorly. This would tend to make the second alternative unlikely. The third possibility, 
namely that change occurred peripherally, is the most likely although it is difficult to see how a change in peripheral anterior chamber depth could have occurred without causing some alteration more centrally.

\section{(c) Axial length}

Myopia could be produced by an increase in the axial length of the eye. We were unable to produce any direct evidence of axial lengthening in this study.

It is known that raising the intraocular pressure increases the volume of the eye(Greeves, I9I3) and so it is possible that the axial length of the globe was increased when tension was raised. Stretching of the sclera to produce myopia would need to be sufficient to overcome the relative hypermetropia produced by the corneal flattening seen in our study.

Eisenlohr, Langham, and Maurice (I962) found that the pressure:volume relationships in the eye were modified when intraocular pressure rose to approximately arterial blood pressure. It could be that at this level blood is forced from the choroid, which becomes relatively thinner. This effect would produce a slight increase in the internal length of the globe which might produce a tendency towards myopia.

\section{(d) Thickness and refractive indices of cornea and lens}

Myopia could be produced by changes in the thickness and/or refractive indices of the cornea and lens. We have no data about refractive indices and can find no reason for this to occur.

The corneal thickness did not change by a measurable amount and this possibility as a cause of myopia can be excluded. There are no data concerning lens thickness. In order to produce myopia the thickness of the lens would need to be increased. This would produce some shallowing of the anterior chamber centrally and this did not occur. We cannot exclude the possibility of posterior lenticonus but cannot see how this could have occurred simply by raising intraocular pressure. We are unable to account for the good correlation between changes in tension and corneal curvature found in this study. It is possible that the corneal flattening resulted from stretching of the sclera behind the limbus as part of the overall expansion of the globe, and until there is evidence to the contrary we are inclined to accept this explanation.

\section{Conclusions}

Variations in tension produce changes in refraction and visual acuity in many eyes. When tension is raised the change is always towards relative myopia although the cornea becomes relatively flatter. As no other change was observed which was likely to produce myopia, it is thought that the main cause lies in the posterior segment.

\section{Summary}

Changes in visual acuity, refraction, and corneal curvature were studied at different levels of intraocular pressure in 42 eyes undergoing investigation for chronic simple glaucoma. It was found that nearly two-thirds showed a change in refraction of -0.12 to $-I \cdot 50 \mathrm{D}$, while the radius of corneal curvature was increased in nearly every case when intraocular pressure was increased. This apparent paradox is discussed. 
We wish to thank Dr. J. Gloster for permission to examine patients under his care and Mr. B. Augier for his help with the statistical aspects of this study.

\section{References}

Draeger, J. (1959) Docum. Ophthal. (Den Haag), 13, 431

Drance, s. M. (1960) A.M.A. Arch. Ophthal., 63, 668

eisenlohr, J. E., LANGHAM, M. E., and MAUMEnee, A. E. (1962) Brit. F. Ophthal., 46, 536

FRIEDENWALd, J. S. (1937) Amer. F. Ophthal., 20, 985

Gloster, J., PERkins, E. S., and POMmier, M. L. (1957) Brit. F. Ophthal., 41, 103

GRAhAM, P., and hollows, F. C. (1964) Trans. ophthal. Soc. U.K., 84, 597

Greeves, R. A. (I913) Proc. roy. Soc. Med., 6, Sect. Ophthal., p. 73

MEHRA, K. S. (1965) Acta ophthal. (Kbh.), 43, 105

PERkins, e. s., and gloster, J. (1957) Brit. F. Ophthal., 41, 93 